\title{
FURTHER REPORT ON INHERITANCE OF HORN AND WOOL COVERING IN SHEEP
}

\author{
T. R. ARKeLL \\ Durham, N. H.
}

This paper represents a review of the experimental work that has been thus far completed in breeding horned and hornless sheep together. Owing to the fact that it is not a good plan to breed ewe lambs, the work has progressed slowly. A large number of the $F_{1}$ generation has been obtained, but comparatively few of the $F_{2}$. The 1912 crop of lambs, it is hoped, will bear from 30 to $40 \mathrm{~F}_{2}$ individuals. We shall then be placed in a position to describe more definitely the manner of inheritance of horns in sheep.

In studying horns we first found it necessary to appoint some common factor whereby we could describe and compare accurately all sizes and degrees of horns. The ratio of circumference to length was taken for this purpose. This is attained in the following manner: Two measurements of length are made from the poll to the tip of the horn, one on the inside and the other on the outside of the horn. An average of these is taken and the result represents the length of the horn. The circumference is taken as close to the poll as possible.

The first problem that presented itself was the effect or relation of age to the ratio; or, in other words whether the ratio was constant at all ages. Without definite knowledge in this regard many errors might easily enter that would greatly depreciate the scientific value of the data. To this end measurements of Dorset rams and ewes were made every month from birth until a constant ratio was attained. It was discovered that not until eighteen months of age did the horns reach a stage of perfect maturity beyond which appreciable fluctuations in size no longer occurred. The circumference at first expands to a greater extent than does the length, consequently giving a less ratio. So far as we have been able to judge from data at hand there seems to be no definite rate of increase in growth, nor is it in any way comparable to the growth of the body. When work of gathering this data was commenced, we had in mind only the desire to be able to recognize the period when variations in horn growth ceased. Since then a new avenue of research has been opened up, namely, variations in the rate of growth and the possibility of an inheritable tendency in this respect.

At three months of age the ratio (length divided by circumference) of horn measurements of the rams averaged in round figures 2.00, 
of the ewes, 1.60; at six months the rams 2.60, the ewes 2.00 ; at one year the rams 3.25 , the ewes 2.50 ; and at eighteen months the rams 3.40 and the ewes 2.70 . The average ratio of a matured horn, according to our measurements of twenty-four Dorset Horn rams and ewes, was for the ram 3.44 and for the ewe 2.72. This, I admit, does not represent altogether a fair average, since only 12 individuals of each sex were included. In order to establish a more exact average, measurements of several hundred sheep should be made. However, in all instances the ratios ran fairly evenly, the difference between the highest and the lowest in the ewes, which was the greatest, being 0.33 points. The difference between the ratios of the horns of the rams and the ewes may be represented by a coefficient which expresses the ratio. of the one in terms of the other. In this instance with the data we have at our disposal the coefficient would be 1.26. However, as I have already pointed out, this factor; owing to the comparatively small number of measurements of typical long horns we have been able to make, should not be adjudged as absolute. We have used it only in making rough comparisons.

Many Rambouillet ewes possess quite large horn excrescences that; however, do not break the skin. These excrescences are not measurable although they sometimes protrude as much as an inch and a half beyond the skull. This peculiar feature we have called, in brief, "a knob." Any horn having a ratio less than 1.00, we have desig-. nated a "scur" and beyond that "short," "medium" or "long" horn as the ratio justifies.

Where reciprocal crosses were made of a long horned sheep with a hornless sheep, the females were invariably polled and the males always possessed some indications of horn growth, varying all the way from minute scurs to a medium-sized horn. The longest horn from such a cross had a ratio of 2.91 and the shortest consisted of a scur with a ratio of 0.32 . Reciprocal crossesof horned father and pollèd mother or vice versa gave horns in the male offspring very similar in character or, at least, no appreciable difference could be discerned. It is true that the average ratio of the horns of male individuals from each cross was 0.26 points higher where the mother was horned, yet this is due to the fact that one individual, compared with the average of this cross, had abnormally long horns. This, however, is a marked exception. By removing it, the average in both instances is virtually the same.

A peculiar feature of the heterozygous horn in this and other crosses comprehends a lack of similarity in size betwixt the right and left 
horns of many individuals. This difference expressed in terms of the ratio is at times as high as 0.45 and the average of all cases, being 76 per cent of the total horned $F_{1}$ generation, 0.18. The right and left long horns of the Dorset are almost invariably uniform although in 6 per cent of cases examined a very slight difference did exist. Nor does one horn possess an advantage in size over the other, for in 52 per cent of total cases the right horn was the longer; in 48 per cent, the left. However, in the $F_{2}$ generation, in so far as our limited data show, this irregularity disappears to a large extent, which doubtless means a return to the pure horned condition, although such horns are not quite so long as the horns of the horned grandparents.

The knob of the Rambouillet ewe is clearly a sort of incipient horn to which, however, sufficient growth stimulus has not been supplied to permit a complete somatic development. So far as our knowledge extends the knob condition exists only in Merino sheep and will be present in females, without producing a scur or horn, through successive generations. Our records show that when crosses with other breeds are made, it disappears, the female offspring possessing either an entire absence or a long horn according to the nature of the mating. When a ewe bearing the knob character is crossed with a long horned ram other than a Merino, the offspring, both rams and ewes, possess long horns. We have had no exception as yet to this rule, our knowledge, however, comprehending but twelve examples. The length of the horns of the $F_{1}$ offspring, although the ratio of length to circumference is less than that for the long horns of the Dorsets, clearly entitles their inclusion in the long horn class. The offspring from matings between a hornless ram and a ewe bearing knobs are in every respect similar to those of a hornless and a long horned sheep: the females show an entire absence of horn growth and the males bear the usual heterozygous intermediate horns. The horn growth (knob) of Rambouillet ewes will at times break through the skin but seldom to form an appreciable horn, usually a mere scab.

Scurs, except where the knobs of Rambouillet females have disrupted the skin, are heterozygous horns. We have tested $4 F_{1}$ rams, bearing heterozygous horns, two scurs, one a small and the other a medium horn, by breeding each upon 3 pure polled and 3 pure horned ewes. The scurs seemed as potent in producing long horns in the offspring as the small or medium horns. Therefore, the results can be combined without rendering their interpretation misleading. Fourteen offspring, 6 rams and 8 ewes, were obtained from the pure polled ewes. Four rams possess heterozygous horns similar to the fathers; 
the other 2 are polled. The ewes are all hornless. Only 11 lambs 6 males and 5 females, were born of the pure horned ewes. Two rams appear to have long horns, although the horns are not fully matured yet; 2 have scurs and the others, short horns. Two females have long horns; the other 2 are polled. The data, I admit, is so scanty, it does not permit of any sweeping inferences, nor can we estimate whether Mendelian proportions are followed. However; in the former case we would expect a complete absence of a horn factor in the germ plasm of the hornless rams, but the character of the ewes can be determined only by subsequent test breeding inasmuch as some may be heterozygous bearing a single horn factor which upon a favorable combination may in a later generation develop a horn growth. In the latter case the horned female apparently possesses a pure long horn and the 4 that are hornless are heterozygous in regard to horns, for their mothers possessed homozygous horns and the father was plainly a heterozygote in that respect, being the product of an assuredly pure hornless male and a pure horned female. Therefore, the hornless $F_{2}$ females must hold in their germ plasm one horn factor.

Matings between hornless sheep invariably produce hornless females and males that are either hornless or possess intermediate horns. The hornless females may be pure or heterozygous which selective breeding alone will show, unless their lineage for several generations is known. The hornless males cannot reproduce a horn. The experience of practical breeders provides proof to this end and in our own breeding operations hornless males bred upon recognizedly pure hornless ewes have never produced in the male offspring the slightest semblance of a horn. The horned males of this cross are clearly heterozygous.

It has been my purpose in this paper to state as concisely and:interp estingly as possible our results at New Hampshire Experimentistation in experimental breeding of sheep in so far as the horn character is concerned. Extensive breeding of sheep for this purpose is a slow. operation, since ewes must remain until they are yearlings before they can be bred satisfactorily. From what proof is already before us it is patently demonstrated that the horn condition is dominant. In heterozygous rams an intermediate horn, varying in size all the way. from a scur to a medium horn, appears. However, in heterozygous ewes no horn whatever develops. The following theory explains thus far satisfactorily this phenomenon. It is evident that the presence of but one horn factor in the germ plasm of the female does not provide sufficient stimulus for the somatic development of even the slightest 
vestige of horn, since the foregoing data shows that the knobs and scurs of Rambouillet ewes transmit upon crossing, long horn qualities in a similar fashion to a pure long horned ewe. This, therefore, points in the latter condition, to the existence in the germ plasm of both horn determiners. It is probable that in the female germ plasm there exists some factor unfavorable to somatic horn growth, or in other words an inhibitor (designated in the table by the symbol I, its absence by i), which is associated with femaleness as a homozygous dominant, but is simplex (heterozygous) in the male, the inhibitor being located on the sex chromosome. Therefore, both horn determiners must be present in the female germ plasm before horn growth can be produced, for the double inhibitor is capable of preventing the development of the single horn $(\mathrm{Hh})$ determiner, but not the double determiner $(\mathrm{HH})$. In the zygote where only a single inhibitor is present, the simplex horn will develop. This theory consequently must presuppose, as well, the female to be duplex in regard to sex (XX); and the male simplex $(\mathrm{Xx})$. This conditions has been found by Guyer (1910) to hold true for man. ${ }^{\mathrm{a}}$

The table on page 566 explains the nature of the matings that have been made. A part of the data derived from breeding experiments with Scottish four-horned sheep has been furnished by Dr. C. B. Davenport of the Station for Experimental Evolution, Cold Spring Harbor, Long Island, with whom this Station coöperates. The actual number of offspring obtained from each mating is given and above them in parentheses is shown in the complex cases the expected proportions of frequency.

Wool covering.-Wool covering of head and legs constitutes an important factor of the modern breeds of sheep. The extent of covering frequently enable the novice to distinguish the different breeds. It is true and is to be regretted that in many instances fashion born of showyard practices has placed an emphasis upon certain styles of wool covering far exceeding the intrinsic value. It has, in fact, become a fad with many breeders who pay more attention, in selecting their breeding animals, to perfection of wool covering and other equally fancy features than to characters of commercial utility.

It is known that some breeds as the Shropshire, have an extensive wool covering on the head, surrounding the eyes and closely approaching the lips. The wool also covers the legs to the pasterns. The opposite of this condition is seen in the Leicester or Suffolk Down

\footnotetext{
a For a more complete report on the inheritance of horng in sheep, see Bul. 160 of the New Hampshtre Experiment Station.
} 
Matings of horned and hornless sheep.

\begin{tabular}{|c|c|c|c|c|c|c|}
\hline \multirow[b]{3}{*}{$\begin{array}{l}\text { soma } \\
\text { gametes }\end{array}$} & \multicolumn{2}{|c|}{ Determiners in germ plasm of } & \multicolumn{4}{|c|}{$\begin{array}{c}\text { Number of horned and hornless } \\
\text { offspring. }\end{array}$} \\
\hline & Male. & Female. & $\mathbf{M a}$ & les. & Fem & ales. \\
\hline & $\begin{array}{l}X x h h l i \text { (hornless) } \\
\text { Xhi } \\
x h i \\
\text { Xxhhli (hornless) }\end{array}$ & $\begin{array}{l}X X h h I I \text { (hornless) } \\
X h I \\
X X h h I I \text { (hornless) }\end{array}$ & horned. & $\begin{array}{l}\text { horn- } \\
\text { less. } \\
4 \\
4\end{array}$ & horned. & $\begin{array}{l}\text { horn- } \\
\text { less. } \\
12\end{array}$ \\
\hline $\begin{array}{l}\text { soma } \\
\text { gametes } \\
\text { zygotes }\end{array}$ & $\begin{array}{l}X x h h I i \text { (hornless) } \\
X h I \\
x h i \\
X x H h I i \\
X x h h I i \text { (hornless) }\end{array}$ & $\begin{array}{l}X X H h H \\
\quad \text { (hornless, simplex) } \\
X H I \\
X h I \\
X X H h I I \text { (hornless) } \\
X X h h I I \text { (hornless) }\end{array}$ & $\begin{array}{l}(2) \\
2\end{array}$ & $\begin{array}{l}(2) \\
2\end{array}$ & $\begin{array}{l}(0) \\
0\end{array}$ & $\begin{array}{l}(2) \\
2\end{array}$ \\
\hline $\begin{array}{l}\text { soma } \\
\text { gametes } \\
\text { zygotes }\end{array}$ & $\begin{array}{l}X x h h I i \text { (hornless) } \\
X h I \\
x h i \\
X x H h I i \text { (horned) }\end{array}$ & $\begin{array}{l}X X H H I I \text { (horned) } \\
X H I \\
X X H h I I \text { (hornless; }\end{array}$ & 15 & 0 & 0 & 24 \\
\hline $\begin{array}{l}\text { soma } \\
\text { gametes }\end{array}$ & $\begin{array}{l}X x H h l i \text { (horned, simplex) } \\
X H I \\
X h I \\
x H i \\
x h i \\
X x H h I i \text { (horned) } \\
X x h h I i \text { (hornless) }\end{array}$ & $\begin{array}{l}X X h h I I \text { (hornless) } \\
X h I \\
\\
X X H h I I \text { (hornless) } \\
X X h h I \text { (hornless) }\end{array}$ & $\begin{array}{c}(0.5) \\
0\end{array}$ & $\begin{array}{c}(0.5) \\
1\end{array}$ & $\begin{array}{l}(0) \\
0\end{array}$ & $\begin{array}{l}(8) \\
8\end{array}$ \\
\hline $\begin{array}{l}\text { soma } \\
\text { gametes }\end{array}$ & 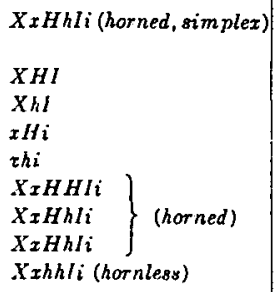 & 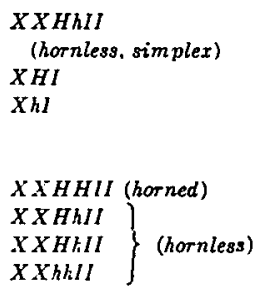 & $\begin{array}{c}(7.5) \\
0\end{array}$ & $\begin{array}{c}(2.5) \\
4\end{array}$ & $\begin{array}{l}(2) \\
1\end{array}$ & $\begin{array}{l}(6) \\
7\end{array}$ \\
\hline $\begin{array}{l}\text { soma } \\
\text { gametes } \\
\text { zygotes }\end{array}$ & $\begin{array}{l}\text { XxHhli (horned, simplex) } \\
X H I \\
X h I \\
x H i \\
x h i \\
X x H H I i \text { (horned) } \\
X x H h l i \text { (horned) }\end{array}$ & $\begin{array}{l}X X H H I I \text { (horned) } \\
X X H h I I \text { (hornless) }\end{array}$ & $\begin{array}{l}(10) \\
10\end{array}$ & $\begin{array}{c}(0) \\
0\end{array}$ & $\begin{array}{r}(4) \\
4\end{array}$ & (4) \\
\hline $\begin{array}{l}\text { soma } \\
\text { gametes } \\
\text { zygotes }\end{array}$ & $\begin{array}{l}X \times H H I i \text { (horned) } \\
X H I \\
x H i \\
X \times H h I i \text { (horned) }\end{array}$ & $\begin{array}{l}X X h h I I \text { (hornless) } \\
X h I \\
X X H h I I \text { (hornless) }\end{array}$ & 5 & $\mathbf{0}$ & 0 & 8 \\
\hline $\begin{array}{l}\text { soms } \\
\text { gametes } \\
\text { zygotes }\end{array}$ & $\begin{array}{l}X x H H I i \text { (horned) } \\
X H I \\
x H i \\
X x H H I i \text { (horned) }\end{array}$ & $\begin{array}{l}X X H H I I \text { (horned) } \\
X H I \\
X X H H I I \text { (horned) }\end{array}$ & 6 & 0 & 14 & 0 \\
\hline
\end{tabular}


where there is no wool on the head in front of the ears nor any on the legs below the knee and the hock. The other breeds represent various gradatory stages between these two distinct types.

Crosses were made of these different types. The greatest area of wool on head, where it extended to the lips, was given a grade of ten; the least, where the head was bare in front of the ears, zero. A similar system was employed in respect to wooling of legs, namely, heavy wooling to pastern received a grade of 10 and bareness on the legs below knee and hock, zero. The wooling on the legs corresponds so closely to that on the head that for convenience I shall discuss only the latter.

The area of wool on the head was obtained by first measuring the face along the nose ridge from the horn pits to the ends of the nostril, underneath from the point of the jaw to the lips, transversely across the head from the point of the jaw to the horn pits and longitudinally along the head from the end of the nostril over the eye to a point which if extended would meet the horn ridge. The distance which the wool descends upon the face is also measured along the same planes. If, per example, the length of the face along the nose ridge is $100 \mathrm{~mm}$. and the wool descends $75 \mathrm{~mm}$. then the wool must cover three-quarters or 75 per cent of the face along that plane. This position is accordingly marked on a drawing representing a standard head and when the other measurements and ratios are obtained a complete drawing can be made showing clearly and precisely how far the wool descends. ${ }^{b}$ Diagrams of wool covering of the father, mother and offspring are made upon the same standard outline of a head, each being represented for the sake of distinction by solid, dash and dotied lines respectively. This method enables one at a glance to recognize the nature of the cross.

In 14 cases where a high grade was crossed with an extremely low one the offspring possessed a grade virtually midway between those of the two parents. In 7 other cases considerable variation existed, but in no instance did the grade of any offspring exceed the grade of the parent possessing the heaviest covering or, for that matter, come within 25 per cent of it. Even in less distinct crosses the wooling of the offspring was usually intermediate. Of $99 F_{1}$ offspring only 12 were not intermediate, and of the exceptions 3 were behind the least advanced parent and 9 equal to the most advanced. Therefore, so far as the foregoing evidence shows, wool covering tends, in the succeeding generation, to form a blend. This character has been studied in

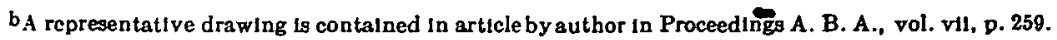


$12 \mathrm{~F}_{2}$ individuals. Eleven show a further reblending or are intermediate to the $F_{1}$ parents who in themselves were intermediate to their parents. One, however, has apparently assumed the type of the father's mother who possessed the highest grade of any of his ancestors. The outline is very similar although the grade of the grandson is a half point less. This evidently points to Mendelian segregation, but since it is the only one of relatively few examples, no inferences can yet be drawn. It is interesting, however, to note the prevalence of blending and reblending which apparently does occur throughout consecutive generations. It should also be stated in closing that wool covering appears to be inherited entirely independent of sex difference, for reciprocal crosses gave in all instances similar results.

\section{DUAL PURPOSE AND TOTAL FAT PRODUCTION}

E. N. WENTWORTH

Ames, Iowa

For a full century the possibility of a dual purpose cow, popularly and for advertising purposes called a "farmer's cow," has been brought' to the attention of the practical farmers, the agricultural press and the agricultural college. All kinds of inducements from a calf nurse to a butter producer have been offered as bait to those momentarily discouraged with special purpose herds. The high price of land and higher cost of production has been cast as a shadow over the beef raiser particularly, and the older writers have dipped into a past when butcher and consumer were not so exacting in their demands, and resurrected, true to their beef tastes, the Milking Shorthorn. Theoretically the two-purpose animal has seemed a nearly accomplished type to the sanguine breeder, and various breeds foreign to America, have had spectacular advents and advertising. In almost all cases mediocrity or even oblivion has greeted both breeder and breed alike. At the present day a few earnest workers still wrestle with the problem, but public favor does not uniformly claim their production. Something must lie behind the problem other than the unrestricted range and live stock outlet of the last century. The writer has looked into the subject from the standpoint of total fat production, and apparently has found one place in which efficiency may be halted. 